\title{
LA ORDEN EUROPEA DE RETENCIÓN DE CUENTAS EN UN PROCESO SEGUIDO EN ESPAÑA: ¿NATURALEZA CAUTELAR O EJECUTIVA?
}

\author{
Faustino CORDón MORENO*
}

\begin{abstract}
SUMARIO: 1 . INTRODUCCIÓN.-2. NATURALEZA Y ALCANCE DE LA ORDEN DE RETENCIÓN.-3. ¿ORDEN DE RETENCIÓN O LAS MEDIDAS PREVISTAS EN EL ORDENAMIENTO NACIONAL?
\end{abstract}

\section{INTRODUCCIÓN}

1. El Reglamento núm. $655 / 2014^{1}$ viene a desarrollar, en una norma vinculante, previsiones que ya estaban contenidas en el «Libro Verde sobre una mayor eficacia en la ejecución de las resoluciones judiciales en la Unión Europea: embargo de activos bancarios», de 24 de octubre de 2006, que tenía fijado como objetivo mejorar las normas sobre ejecución de los créditos pecuniarios en Europa, consideradas con frecuencia el «talón de Aquiles» del espacio judicial europeo en materia civil.

2. Para buscar remedio a esta situación, un estudio encargado por la Comisión en 2002 propuso diversas medidas y, en particular, estas tres: «La creación de una orden europea de embargo de activos bancarios, una orden precautoria europea para el mismo fin y una serie de medidas para aumentar la transparencia de los bienes del deudor». La solución — se dice en el Libro Verde- " podría ser crear una orden europea de embargo de activos bancarios que permitiera garantizar al acreedor la cantidad que se le adeuda o que él reclama impidiendo la retirada o transferencia de fondos en poder del deudor a una o más cuentas bancarias en el territorio de la Unión Europea». Una orden de este tipo tendría solo un efecto precautorio, es decir, cautelar o ase-

* Catedrático de Derecho Procesal en la Universidad de Navarra (fcordon@unav.es).

1 Reglamento (UE) núm. 655/2014, del Parlamento Europeo y del Consejo, de 15 de mayo, por el que se establece el procedimiento relativo a la orden europea de retención de cuentas a fin de simplificar el cobro transfronterizo de deudas en materia civil y mercantil, $D O$ L núm. 189, de 27 de junio de 2014. 
gurativo de la medida ejecutiva de embargo adoptada, pero no de realización forzosa, porque su efecto "se limitaría a bloquear los fondos del deudor en una cuenta bancaria sin transferirlos al acreedor. Así entendida, la orden de embargo dictada en un Estado miembro sería reconocida y podría ejecutarse en toda la Unión Europea sin necesidad de declarar su fuerza ejecutiva»; y «podría establecerse bien mediante la concepción de un procedimiento europeo específico y nuevo que se aplicaría además de las medidas previstas en la legislación nacional, bien mediante la armonización, a través de una directiva, de las normas nacionales de los Estados miembros relativas al embargo de activos bancarios».

3. Pues bien, el Reglamento núm. 655/2014, que aborda estas previsiones, opta por la primera de las soluciones mencionadas, es decir, crea un procedimiento propio de la UE, aunque no parece recoger las tres medidas propuestas en el estudio realizado en 2002 antes mencionadas porque, al menos nominalmente, prescinde de la primera de ellas ( orden europea de embargo de activos bancarios»). Más adelante precisaré este tema.

4. Las consideraciones que a continuación realizo se centran en un aspecto concreto que tiene que ver con la naturaleza y el alcance de la orden de retención, aunque las completaré con un apunte breve sobre la regulación de la misma en el Reglamento núm. 655/2014 como alternativa a las medidas del Derecho nacional que persiguen la misma finalidad. Para ello tomo en consideración uno de los supuestos en que el Reglamento resulta aplicable (véanse su considerando 10 y también el art. 3): a saber, aquel en que «el órgano jurisdiccional que conoce de la solicitud de la orden de retención se encuentre en un Estado miembro y la cuenta bancaria afectada por dicha orden se tenga en otro Estado miembro». Y dentro de él contemplo la hipótesis de un procedimiento iniciado - o por iniciar - en España (lo que supone que corresponde al juez español la competencia para dictar la orden de retención, conforme al art. 6 del Reglamento, y que todas las cuestiones procesales que no estén específicamente reguladas en el Reglamento se regirán por el Derecho español: art. 46.1), en el que, como ya he dicho, dicha orden «estará a disposición del acreedor como alternativa a las medidas cautelares previstas en el Derecho nacional» (art. 1.2); porque, con palabras del considerando 6. ${ }^{\circ}$, el procedimiento que establece el Reglamento «debe constituir un medio complementario y opcional para el acreedor, que conserva plena libertad de recurrir a cualquier otro procedimiento establecido en el Derecho nacional para la obtención de una medida equivalente».

\section{NATURALEZA Y ALCANCE DE LA ORDEN DE RETENCIÓN}

5. Dispone el art. 5 del Reglamento (véase también su considerando 11) que el acreedor (español) podrá solicitar (ante un juez español) una orden de retención (del saldo existente en una cuenta bancaria situada en otro país) en estas dos situaciones: $1 .^{\mathrm{a}}$ ) antes de que incoe un procedimiento en un Estado 
miembro contra el deudor sobre el fondo del asunto, o en cualquier fase de ese procedimiento hasta el momento en que se dicte la resolución judicial o se apruebe o concluya una transacción judicial, y $2 .^{\mathrm{a}}$ ) después de que haya obtenido en un Estado miembro una resolución judicial, una transacción judicial o un documento público con fuerza ejecutiva que obligue al deudor a pagar una deuda a su favor. En realidad, pues, se distinguen tres situaciones distintas en que puede solicitarse la orden: antes de iniciarse un proceso declarativo para la reclamación de la deuda dineraria o durante la pendencia del mismo en primera instancia; mientras está pendiente de algún recurso interpuesto por el deudor y hasta que se obtenga una sentencia de condena firme que sea título ejecutivo conforme al art. 517.2.1 de la Ley 1/2000, de 7 de enero, de Enjuiciamiento Civil ${ }^{2}$ (en adelante, LEC); y una vez alcanzada firmeza por la resolución judicial, supuesto al que se equipara el caso en que el acreedor dispone de un título ejecutivo negocial. La distinción de estos tres supuestos me parece clara por lo que a continuación digo, aunque es dudoso si el segundo de ellos (crédito reconocido por una resolución judicial no firme) hay que incluirlo en la primera o en la segunda de las situaciones previstas en el art. 5 del Reglamento. La cuestión es relevante porque, como diré, de ello dependerá que en tal caso el acreedor pueda solicitar las medidas de investigación del art. 14 del Reglamento.

6. En el primer caso, la orden de retención es una genuina e indiscutible medida cautelar, porque su finalidad es asegurar la efectividad de la tutela judicial que pueda otorgarse; la orden de retención podrá pedirse (y acordarse), de acuerdo con las previsiones del Reglamento núm. 655/2014, ante litem o durante la pendencia del procedimiento (de declaración), y siempre inaudita parte debitoris (art. 11), sin necesidad, además, a diferencia de lo que ocurre en Derecho interno, de justificar razones de urgencia o necesidad (véase el art. 730.2 LEC).

7. En el segundo (pendencia del proceso de declaración en sede de recursos interpuestos por el deudor), la orden de retención prevista en el Reglamento sigue teniendo sentido como medida cautelar, porque la misma se ofrece al acreedor como alternativa a la que, también como medida cautelar, puede solicitar en el Derecho interno (véase el art. 730.4 LEC); pero en el bien entendido que si el acreedor insta la ejecución provisional, cuando la misma se despache, "se alzarán las medidas cautelares que se hubiesen acordado y que guarden relación con dicha ejecución» (art. 731.2 LEC), quedando sustituidas por las ejecutivas que se adopten, entre ellas la misma orden de retención conforme a las previsiones del Reglamento, que se ha podido solicitar y acordar, pero para garantizar ahora la medida ejecutiva del embargo de la cuenta previamente acordado. Lo mismo ocurrirá si el recurso es estimado, produciéndose el alzamiento de la medida cautelar; y en el Derecho interno de oficio (art. 744.1 LEC), sin necesidad de que el deudor lo solicite, como parece exigir el Reglamento núm. 655/2014 [art. 33.1.f)].

2 BOE núm. 7, de 8 de enero de 2000. 
8. Obsérvese que, si se entiende que este caso está incluido en el segundo de los supuestos del art. 5 del Reglamento, este alcance de la orden como medida cautelar es limitado, porque no se producirá cuando el acreedor disponga de un título ejecutivo negocial y previsiblemente tampoco cuando el crédito sea el resultado de una transacción judicial, por recoger la misma un acuerdo entre las partes en conflicto que excluirá en la generalidad de los casos el recurso contra la resolución judicial que la apruebe u homologue.

9. En el tercer caso (crédito documentado en una resolución judicial firme o en un título ejecutivo negocial), en cambio, me parece que la consideración de la orden de retención como una medida cautelar debe ser precisada. Ciertamente el Reglamento habla de medidas cautelares también en este caso (arts. 1.2 y 7.1, por ejemplo) y esta naturaleza de la orden (también en todos los supuestos) es defendida en la doctrina, por ejemplo, por mi compañera de foro Carmen Senés; aunque no me parece que sea un argumento a favor que el efecto de la orden se limite a bloquear los fondos del deudor en una cuenta bancaria sin transferirlos al acreedor, porque la transferencia forma parte de la realización forzosa y esta no agota las actuaciones ejecutivas, ya que también lo son el embargo y las medidas de garantía del mismo.

10. Sin embargo, en mi opinión, cuando el acreedor tiene un título ejecutivo, judicial o negocial, es discutible que la orden de retención que puede solicitar sea -o tenga el alcance de- una medida cautelar en sentido estricto, porque en este caso la efectividad de la tutela jurídica queda asegurada con estas dos medidas no ya cautelares, sino ejecutivas: el embargo de bienes (del saldo existente en la cuenta) que el acreedor puede solicitar en la demanda ejecutiva (art. 549.1.3) y el letrado de la administración de justicia (en adelante LAJ) acordar mediante decreto tan pronto como el juez dicte el auto conteniendo la orden general de ejecución y acordando el despacho de la misma (art. 551.2-1 LEC), y la adopción de las medidas de garantía del mismo que pueden acordarse; entre otras, la orden de retención de las concretas cantidades que sean embargadas. Cuando estas cantidades se encuentren en cuentas situadas en el extranjero, dicha orden podrá solicitarse - y acordarse- conforme a las previsiones del Reglamento, que se ofrecen como alternativa a su regulación interna (art. 621.2 LEC). Pero con ella se asegura no la efectividad de la tutela que pueda otorgarse en un proceso de declaración, sino una medida ejecutiva, el embargo del saldo de la cuenta previamente acordado. Su finalidad es, por tanto, solo precautoria o de garantía de la traba; la realización de la suma embargada mediante su entrega al acreedor ejecutante requiere el previo reconocimiento y ejecución de la sentencia o título ejecutivo de que se trate y, por eso, dispone el art. 34 del Reglamento que la ejecución de la orden de retención se dejará sin efecto por «haberse desestimado, en el Estado miembro de ejecución, la ejecución de la resolución judicial, la transacción judicial o el documento público con fuerza ejecutiva cuya ejecución trataba el acreedor de garantizar por medio de la orden».

11. No es imaginable que este acreedor, titular de un título ejecutivo — judicial o negocial—, solicite la orden de retención, como medida cautelar, 
antes de iniciar el proceso de ejecución, cuando puede presentar la demanda (ejecutiva) y solicitar en ella directamente la medida ejecutiva (el embargo del saldo) y esta orden de retención de la cuenta como medida de garantía del mismo. Ciertamente sería posible, pero con una eficacia muy limitada, porque resultaría aplicable la norma del art. 10 del Reglamento, que le impone la carga de presentar la demanda en un plazo relativamente breve a partir de la presentación de la solicitud o, en su caso, de la fecha en que se dictó la orden.

12. Y todavía es menos imaginable que la solicite (como medida cautelar) en la misma demanda ejecutiva, o con posterioridad, con la finalidad de asegurar la tutela (ejecutiva) demandada hasta el momento en que el LAJ dicte el decreto acordando el embargo y la medida de garantía del mismo en que la orden de retención consiste (que como medida ejecutiva sustituiría a la previa medida cautelar). La demanda ejecutiva presentada abre un proceso de ejecución, en el que el juez, a la vista de la misma, dictará un auto conteniendo la orden general de ejecución, al que seguirá inmediatamente el decreto del LAJ acordando, entre otras, «las medidas ejecutivas concretas que resultaren procedentes, incluido si fuera posible el embargo de bienes» (art. 551.2.1 LEC). Se trataría, por tanto, de medidas cautelares con un plazo de caducidad muy breve porque, como digo, dictado ese decreto por el letrado de la administración de justicia, las medidas cautelares se convierten en ejecutivas.

13. Pero es que, en mi opinión, no solo no es imaginable que la orden de retención se solicite en estos casos como medida cautelar, sino que tampoco es posible, salvo que se entienda que el concepto de medidas cautelares del Reglamento núm. 655/2014 difiere del contenido en la LEC; porque, en el Derecho español, las medidas cautelares tienden a asegurar, en palabras del art. 721 de la LEC, la efectividad de la sentencia, previniendo las repercusiones perjudiciales que la duración del proceso puede provocar. De aquí que disponga el art. 726.1 de la misma Ley que deben «ser exclusivamente conducentes a hacer posible la efectividad de la tutela judicial que pudiera otorgarse en una eventual sentencia estimatoria, de modo que no pueda verse impedida o dificultada por situaciones producidas durante la pendencia del proceso correspondiente». De lo dispuesto en ambos preceptos deriva que las medidas cautelares se adoptan siempre en el proceso de declaración y con estas dos consecuencias: a) una vez dictada la sentencia firme, no cabe solicitar ni adoptar medidas cautelares, sino solo medidas ejecutivas, y $b$ ) la terminación del proceso principal lleva consigo la de la medida cautelar acordada; si la sentencia es desestimatoria, porque ya no hay nada que asegurar; si es condenatoria, porque se transforma en medida ejecutiva (art. 731).

14. Dicho con otras palabras, la LEC formula con toda claridad la concepción clásica, estrictamente asegurativa (de la efectividad de la tutela que se pueda otorgar), de las medidas cautelares y, por eso, resalta como nota esencial de las mismas su instrumentalidad: la tutela cautelar no constituye una finalidad en sí misma, sino que se halla necesariamente vinculada a la sentencia (o al laudo) que puede dictarse en el proceso principal, cuya efectividad práctica trata de asegurar. 
15. En definitiva, me parece que la orden de retención, en estos casos, tiene una finalidad asegurativa sí, pero de una medida ejecutiva (el embargo del bien), que es la que estrictamente asegura la efectividad de la tutela; por eso, la naturaleza «cautelar» del embargo (ejecutivo) es defendida por un sector de la doctrina, aunque me parece que equivocadamente porque la finalidad del embargo ejecutivo, a diferencia de la que tiene el embargo preventivo, no es asegurar, sino afectar el bien a la ejecución con vista a su realización forzosa para satisfacer el derecho del acreedor. No puede sostenerse que la orden de retención opere al margen del embargo; en estos casos en que el acreedor tiene un título ejecutivo, no tiene existencia autónoma porque solo puede acordarse si existe un embargo y, por eso, goza de la misma naturaleza que este (ejecutiva).

16. Entiendo que a ello se refería el Libro Verde al que antes hice referencia, cuando habla de la creación de «una orden europea de embargo de activos bancarios». Y a ello hay que entender que se refiere el art. 20.c) del Reglamento cuando dispone que la retención durará «hasta que surta efecto, respecto de los fondos retenidos, una medida destinada a ejecutar una resolución judicial, una transacción judicial o un documento público con fuerza ejecutiva obtenido por el acreedor en relación con el crédito que se pretendía garantizar mediante la orden de retención»; esa "medida destinada a ejecutar» no puede ser otra que la orden de transferencia del saldo retenido al acreedor, es decir, la realización del bien embargado y no el embargo mismo: no tendría sentido defender que la orden de retención es solo una medida cautelar que dura hasta que se dicte la medida ejecutiva de embargo cuando este embargo precisa ser garantizado para asegurar la realización del bien trabado.

17. A la vista de las consideraciones anteriores, se puede decir que, no obstante caracterizar el Reglamento la orden de retención de cuentas como medida cautelar en todos los casos, su artículo quinto contempla dos realidades diferentes: una medida cautelar en sentido estricto y una medida de aseguramiento o garantía de una actuación ejecutiva. Porque son realidades diferentes en el plano procesal, los requisitos son distintos en uno y otro caso. En ambos, ciertamente, exige el Reglamento la existencia de periculum in mora (art. 7.1), porque en uno y otro existe un riesgo, derivado de la propia duración del proceso (de declaración o de ejecución), de que puedan producirse, de no adoptarse las medidas solicitadas, situaciones que impidan o dificulten bien la ejecución de la sentencia o, en general, la efectividad de la tutela que pudiera otorgarse en una eventual sentencia estimatoria (art. 728 LEC), bien la satisfacción del acreedor ejecutante. Pero solo en el primero de los casos se requiere con claridad -igual que en el Derecho interno (véase el art. 728 LEC) - la existencia de fumus boni iuris (art. 7.2), que es un elemento esencial de las medidas cautelares, pero no de las ejecutivas, que tienen la cobertura no de la probabilidad de la existencia del derecho, sino la certeza de la misma proporcionada por el título ejecutivo; y solo en el primero también es preceptiva la prestación de caución por el acreedor, aunque excepcionalmente el juez puede dispensar de ella (véase el art. 12.1), como ocurre en 
otros casos (por ejemplo, en el orden concursal: art. 17.2 LC); cuando la orden de retención se solicita por un acreedor con su crédito documentado en una resolución judicial o en un título ejecutivo negocial la caución es potestativa (el juez podrá exigir, dice el art. 12.2), aunque en los casos en que se solicite y acuerdo dentro del proceso de ejecución no tiene sentido la exigencia, salvo que se entienda que lo es para asegurar los daños y perjuicios producidos en el caso de estimarse la oposición a la ejecución o la responsabilidad en que puede incurrir según lo dispuesto en el art. 13 del Reglamento.

\section{3. ¿ORDEN DE RETENCIÓN O LAS MEDIDAS PREVISTAS EN EL ORDENAMIENTO NACIONAL?}

18. Decía antes que el Reglamento núm. 655/2014 ha creado un procedimiento propio de la UE, que se pone a disposición del acreedor como alternativa a las medidas previstas con la misma finalidad en el Derecho nacional. Obviamente, la opción por uno u otro sistema - del Reglamento o del Derecho nacional- dependerá de las ventajas que el acreedor vea en ellos. Por tanto, la cuestión a dilucidar es si el sistema del Reglamento ofrece ventajas sobre el del Derecho interno, y la respuesta afirmativa me parece evidente.

19. Veamos lo que ocurre en cada uno de los supuestos previstos:

20. 1..$\left.^{\circ}\right)$ El acreedor, también en el sistema del Derecho interno español, puede solicitar como medida cautelar, antes de iniciar un procedimiento judicial (de declaración) o pendiente el mismo y hasta la sentencia firme (art. 730.4 LEC), una orden de retención del saldo de una cuenta existente en una entidad financiera ubicada en otro país; aunque dicha orden no esté prevista nominatim, podrá solicitarse - y el juez acordarla- por el sistema abierto de medidas cautelares introducido por la LEC (véase su art. 726). La medida cautelar podrá concederse inaudita parte, siempre que se acrediten razones de urgencia o necesidad (art. 730.2), o previa audiencia del deudor, que es la regla general (art. 730.1); pero solo en el segundo caso las resoluciones correspondientes «serán reconocidas en los demás Estados miembros sin necesidad de procedimiento alguno» (art. 36.1 del Reglamento núm. 1215/2012) ${ }^{3}$, porque las medidas provisionales y cautelares ordenadas por el órgano jurisdiccional sin que el demandado haya sido citado a comparecer «no deben reconocerse ni ejecutarse en virtud del presente Reglamento, a no ser que la resolución que contenga la medida sea notificada al demandado antes de su ejecución» [considerando 33 y art. 1.a) del Reglamento núm. 1215/2012].

21. En este caso, el sistema del Reglamento 655/2014 ofrece dos ventajas evidentes sobre el de Derecho interno: $a$ ) la medida cautelar se acordará

\footnotetext{
3 Reglamento (UE) núm. 1215/2012, del Parlamento Europeo y del Consejo, de 12 de diciembre, relativo a la competencia judicial, el reconocimiento y la ejecución de resoluciones judiciales en materia civil y mercantil (refundición), DO L núm. 351, de 20 de diciembre de 2012.
} 
siempre inaudita parte debitoris y sin necesidad de justificar la urgencia o la necesidad (art. 11), extendiéndose la aplicación del principio a la sustanciación del eventual recurso del acreedor frente a la resolución desestimatoria de su solicitud (art. 21.3), yb) la resolución correspondiente «será reconocida en los demás Estados miembros sin necesidad de procedimiento alguno y tendrá fuerza ejecutiva en los demás Estados miembros sin necesidad de una declaración de fuerza ejecutiva» (art. 22).

22. En cambio, no es aplicable en estos casos la posibilidad de investigar las cuentas del deudor prevista en el art. 14, por lo que la eficacia de la medida cautelar se supedita a que el acreedor identifique el banco y la cuenta que contenga el saldo sobre el que se pretende que actúe la orden de retención. Es dudoso que la previsión del art. 14 sea aplicable a los casos en que el acreedor tiene su crédito reconocido en una sentencia judicial, pero la misma se encuentra recurrida por el deudor porque, aunque se cuente con un pronunciamiento condenatorio, el mismo puede ser revocado, por lo que no parece que el mismo sea suficiente para legitimar actuaciones que pueden afectar a derechos fundamentales del deudor.

23. 2. ${ }^{\circ}$ ) Decía antes que es discutible que el acreedor que tiene documentado su crédito en un título ejecutivo (resolución judicial firme o título ejecutivo negocial) pueda interesar - y el juez acordar-la orden de retención como medida cautelar dentro del proceso de ejecución (o con anterioridad al mismo). En este proceso (de ejecución) la orden de retención podrá pedirse, conforme a las previsiones del Reglamento núm. 655/2014, como medida encaminada a garantizar o asegurar el embargo previamente acordado (inaudita parte) del saldo existente en la cuenta corriente, si esta es conocida, y si no lo fuera, activar la investigación judicial encaminada a la obtención de información sobre cuentas prevista en el art. 14. Y todo ello -la medida de garantía y, en su caso, la investigación previa- podrá acordarse y llevarse a cabo, conforme a las previsiones del Reglamento núm. 655/2014, en el país de ejecución directamente, sin el previo reconocimiento del título ejecutivo.

24. Por ello, las ventajas del sistema del Reglamento son también manifiestas, ya que permite desvincular la orden de retención, como medida de garantía, del embargo garantizado, dotándola de una eficacia directa.

Palabras clave: orden de retención, protección del crédito, medida cautelar, medida ejecutiva.

Keywords: account preservation order, protection of claims, interim relief, enforcement measure. 